\title{
STUDIES ON MECHANICAL AND THERMAL PROPERTIES OF INFRARED AND THERMALLY CURED GLASS-EPOXY COMPOSITES
}

\author{
Kiran Kumar $\mathbf{P}^{1}$., Raghavendra N.V²., Sridhara B.K. ${ }^{3}$ \\ ${ }^{1}$ Research Scholar, Department of Mechanical Engineering, B.N.M.Institute of Technology, Bangalore, India. \\ ${ }^{2,3}$ Department of Mechanical Engineering,The National Institute of Engineering, Mysore, India \\ Email: ${ }^{1}$ kiran_1975@ rediffmail.com
}

\begin{abstract}
Experiments were carried out on three different types of varying mass density $\mathrm{E}$ glass fiber layers with epoxy matrix for the composite laminates. First set of laminates were reinforced with layers of $200 \mathrm{gsm}$ (grams per square meter) woven glass fibers, second set with layers of $360 \mathrm{gsm}$ woven glass fibers and the third set with layers $200 \mathrm{gsm}$ sandwiched between $360 \mathrm{gsm}$ woven glass fibers. The matrix used in this investigation is epoxy amine system processed by infrared and thermal curing methods. Infrared and thermal curing was accomplished by a custom made infrared and thermal processing chamber, mounted with infrared heater operating in the wavelength range of 3 to 8 micrometers. Thermo mechanical properties of the infrared cured composite laminates in comparison with thermal cured laminates. The values thus obtained help the designers in understanding the reinforcement combination of glass fiber layers of varying gsm (thickness) in order to taylor make the properties according to the required thickness of the laminate or maintain the optimum thickness of the final product without compromising the mechanical properties. Finally the properties of Infrared cured composites are comparable or even better than the thermal cured composites. Infrared curing method has resulted in the curing time reduction by 40percent. The combination of varying 360 and $200 \mathrm{gsm}$ woven glass fiber layers has resulted in values lying between those of 360 and $200 \mathrm{gsm}$ laminates.
\end{abstract}

Key words: Polymer composites, woven glass fibers, Infrared (IR) curing, Thermal curing, Glass transition temperature(Tg), Mechanical properties.

\section{INTRODUCTION}

As there is need for newer products of better performance, we see continuous improvement in prevailing methods in every area of product development. Developments take place in the area of design, process, manufacturing and testing. Innovative research is the only key to this. This has resulted in working with various combinations of available materials and giving birth to a new hybrid material which has the advantages of both the parent materials and superior properties compared to them. In the area of FRP composites hybrids play a vital role. Understanding the properties of the matrix material and reinforcement material and identifying their behavior as a composite is a phenomenal task.

Hybrid composites are more advanced composites as compared to conventional FRP composites. Composite material by definition is heterogeneous. The individual laminas that constitute a continuous fiber reinforced composite laminate are anisotropic. Small changes in stacking sequence or processing parameters may alter the mechanical properties. Hybrids can have more than one reinforcing phase and a single matrix phase or single reinforcing phase with multiple matrix phases or multiple reinforcing and multiple matrix phases. ${ }^{[1-3]}$ They have better flexibility as compared to other fiber reinforced composites. By combining two or more types of fibers, it is possible to club the advantages of both the fibers while simultaneously mitigating their less desirable qualities. Normally, one of the fibers in a hybrid composite is a high-modulus and high-cost fiber such as carbon, boron and the other is usually a low-modulus fiber such as E-glass and Kevlar. The high-modulus fiber provides the stiffness and load bearing qualities, whereas the low-modulus fiber makes the composite more damage tolerant and keeps the material cost low. The mechanical properties of a hybrid composite can be varied by changing volume ratio and stacking sequence of different plies. The other important aspect of hybrids is maintaining the required thickness with improved properties, which is highly important for aerospace applications.

Curing is one of the major concerns in the processing of polymer composites. Curing leads to the final strength of composite. Curing is the polymerization 
of monomers to form the polymer chain. ${ }^{[4]}$ The proper cure cycle design is important; the flow of heat into the composite should be uniform. ${ }^{[5]}$ Uneven curing leads to thermal stress and reduce the strength. The composite should be free from voids and other defects. Therefore innovative methods of curing like Microwave, $\mathrm{RF}$, UV, and Infrared are playing prominent role as alternative to conventional thermal curing ${ }^{[6-9]}$.

Processing time required for curing of polymer composites vary according to the type of matrix resin, hardeners selected, reinforcement and the type of curing selected whether thermal or radiation method of cure. ${ }^{[10-13]}$. The cure cycle consists of ramping and soaking at different temperatures, deciding the optimum cure cycle for the process selected is a herculean task. ${ }^{[14]}$ Comparison of mechanical properties of the composites cured under various combinations is required in order to understand the variation of strength. ${ }^{[15]}$. Tensile and flexural strength is a fiber dominating property. Glass transition temperature $(\mathrm{Tg})$ explains the degree of cure of the composite. The $\mathrm{Tg}$ has a direct correlation with the mechanical properties of the composites has proved by earlier researchers. Radiofrequency is commonly used for heating metals, food products and fibers. Microwaves are used for heating rubber, food products and ceramics. Infrared is used for heating metals, food products, and also used in medical applications. Ultraviolet is used for thin film drying and packaging. Many researchers have worked on UV, Microwave and RF methods. Very few researchers have worked on Infrared curing of composites and this area is unexplored till date. IR can rapidly heat components and is ideally suited for flat surfaces. It offers fast curing rate precise control, high efficiency and minimal environmental impact. Electric infrared equipment has significantly higher energy efficiencies than conventional thermal processing equipment. Industrial applications of Infrared heating include adhesives and coatings, glass and ceramics, metal processing, medical, and packaging, plastics and rubber, printing, textiles and wood ${ }^{[7]}$. Different methods of curing are in practice such as thermal curing, microwave curing, and ultraviolet curing. Several experimental studies have reported the successful use of radioactive heating to produce high quality FRP composites, however there is very limited data available in publications on IR curing.
The major limitation of thermal curing processes is long curing schedule and high power consumption in the production of FRP products. ${ }^{[16-18]}$ Infrared curing can be better alternative as compared to thermal curing. In this work, this technology has been extended for curing the FRP laminates. Different Infrared schedules were studied in detail for curing GFRP laminates. Infrared is ideally suited for flat surfaces. The wavelength of $I R$ radiation ranges from $10^{-6}$ to $10^{-4}$ meters. Different polymeric resins have different absorption characteristics. Proper range of Infrared source has to be selected for curing depending on the type of resin.

It has the advantages of lower energy consumption \& less amount of heat loss. Infrared is transmitted in 3 energy bands. Short wave ( 0.76 to 2.3 micrometers) used or complex part shapes. Medium wave (2.3 to 3.3 micrometers) used for curing coatings on objects. Broad Wave (3 to 8 micrometers) used for laminates \& packing machines. Infrared in the broad wave range of 2 to 8 micrometers is useful for curing of polymer composites. Infrared can be effectively utilized for curing of polymer composite laminates [19 $-23]$.

The aim of the present study is to understand the efficacy of infrared curing of composites with reference to conventional thermal curing of composite laminates by reinforcing with varying mass density $E$ glass fiber layers without changing the epoxy matrix. The curing of laminates was carried out in a custom made programmable $\mathbb{I R}$ and thermal curing oven.

\section{EXPERIMENTAL DETAILS}

\section{A. Materials used for Preparation of Laminates}

The polymer matrix used in this investigation is bifunctional diglycidyl ether of bisphenol A (DGEBA) type epoxy resin (LY556). The curing agent used is triethylene tetramine TETA (HY 951). The reinforcement used is bidirectional, E-glass fabric with a fiber orientation of $0^{0} / 90^{\circ}$ and a fabric weight of $360 \mathrm{grams}$ per square meter and 200grams per square meter, bi-directional (BID) E-glass woven fabrics M/s Suntech Fibers Pvt Ltd, Bangalore, India.

The laminates of standard size $200 \times 200 \mathrm{~mm}$ and $3 \mathrm{~mm}$ thick were considered for all the tests, The resin density is $1.2 \mathrm{~g} / \mathrm{cm}^{3}$ and the glass fiber density 
is $2.54 \mathrm{~g} / \mathrm{cm}^{3}$, based on the weight ratio of $65: 35$ that is glass fibers to resin ratio for the laminate size of $200 \times 200 \mathrm{~mm}$ the no of glass fibers layers were calculated. In case of combination of glass fibers of varying gsm the ratio of 200 to $360 \mathrm{gsm}$ woven glass fibers were in the ratio of 40: 60. The no of glass fiber layers required were finalized after preliminary tests to verify the overall thickness of the laminate. First set of laminates had 13 layers of $360 \mathrm{gsm}$ woven glass fibers as reinforcement, second set of laminates had 21 layers of $200 \mathrm{gsm}$ woven glass fibers as reinforcement and third set of laminates were prepared with 9 layers of $200 \mathrm{gsm}$ woven glass fiber sandwiched between the 5 layers of $360 \mathrm{gsm}$ on either side that is total number of layers were equal to 19 .

\section{B. Preparation of laminates}

Glass fiber fabrics of $200 \mathrm{~mm} \times 200 \mathrm{~mm}$ were heated in the thermal oven to a temperature of $120^{\circ} \mathrm{C}$ to remove moisture and then the weight of the glass fiber fabric was noted. Hand lay up method was used for preparing the laminates. The fiber weight fraction was maintained at $65 \pm 2 \%$ for all the laminates. Each layer of glass fiber was laid on the mould surface and applied a coat of resin by hand brushing and using roller the excess resin was removed. The procedure was continued for all the thirteen layers. The laminate was allowed to cure at room temperature for $24 \mathrm{hrs}$.

For the preparation of third set of laminates 5layers $200 \mathrm{~mm} \times 200 \mathrm{~mm}$ of $360 \mathrm{gsm}$ were laid and then 9layers $200 \mathrm{~mm} \times 200 \mathrm{~mm}$ of $200 \mathrm{gsm}$ were laid on the surface of $360 \mathrm{gsm}$ and again 5 layers $360 \mathrm{gsm}$ layers were laid on top it, in order to sandwich the 200 gsm layers.

\section{Curing of laminates}

Elevated temperature post curing of GFRP laminates was conducted in the custom designed hybrid (infrared and thermal) oven. Thermal (hot-air) curing of the composite laminates was conducted as per polymer supplier's recommendation. The custom designed Infrared and hot-air curing system has a 400 $\times 400$ SS chamber mounted with IR heater of 3 to8micrometer wavelength of $2 \mathrm{KW}$ capacity and four thermal coil heaters for Hot-air curing of $2 \mathrm{KW}$ each. The chamber is provided with blower to circulate the air inside the chamber to maintain uniform temperature inside the oven. Ceramic board of $50 \mathrm{~mm}$ thick insulation is used to avoid the heat loss to surroundings. The chamber has flexibility of switching over to the Infrared heating mode or thermal according to requirement or combination of both if required. The thermal heating mode inside the chamber can be programmed according to the schedule of ramping and soaking temperature. Infrared curing has to be manually controlled according to the requirement. The temperature is measured by using noncontact type infrared pyrometer. Temperature is measured at different points on the laminate through the vents provided in the chamber. The vents are opened only at the time of temperature measurement. After curing of each laminate the system has to be brought to room temperature condition and then the next cycle of experiments is started.

\section{Thermal Curing of GFRP laminates:}

The $3 \mathrm{~mm}$ thick glass-epoxy laminates were allowed to cure at room temperature for 24 hours. Then the post curing was done in3 steps, room temp to $50^{\circ} \mathrm{C}$ ramping in 10 minutes and soaking for 30 minutes then ramping from $50^{\circ} \mathrm{C}$ to $70^{\circ} \mathrm{C}$ in 10 minutes and soaking for 60 minutes and again ramping up to $85^{\circ} \mathrm{C}$ for 10 minutes and soaking in this temperature for 120minutes and then bringing down to room temperature in 30 minutes.

\section{E. Infrared (IR) Curing of GFRP laminates:}

After repeated trails on different $I R$ cure schedules the final schedule was decided The $3 \mathrm{~mm}$ thick glass-epoxy laminates were allowed to cure at room temperature for $24 \mathrm{~h}$. Then the post curing was done in3 steps, room temp to $50^{\circ} \mathrm{C}$ ramping in 10 minutes and soaking for 10 minutes then ramping from $50^{\circ} \mathrm{C}$ to $70^{\circ} \mathrm{C}$ in 10 minutes and soaking for 20minutes and again ramping up to $85^{\circ} \mathrm{C}$ for 10 minutes and soaking in this temperature for 60 minutes and then bringing down to room temperature in 30 minutes and the amount of time saved is shown in Fig. 1. 


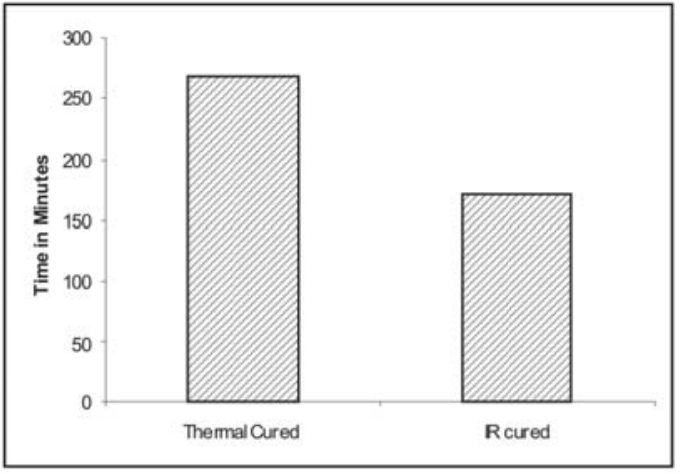

Fig. 1. Processing time consumption comparative graph of Infrared and thermal curing

\section{RESULTS}

A. Determination of tensile and flexural strength.

All the laminates cured by Infrared and thermal process were cut to the required dimensions as per ASTM standards. Tensile Test samples were prepared according to ASTM D638 specifications, Flexural test samples were prepared as per ASTM D790.Tests were conducted using LYODS Universal Testing machine with a 100KN load cell. The crosshead speed maintained was $2 \mathrm{~mm} / \mathrm{min}$. A minimum of five replicate trials was conducted to ensure the repeatability of test data. The tensile stress strain plot is shown in figure 2. and 3. for both infrared cured and thermal cured laminates. The tensile strength reflects the efficacy of the Infrared curing process on the laminates. The improved values are the result of Infrared curing method.

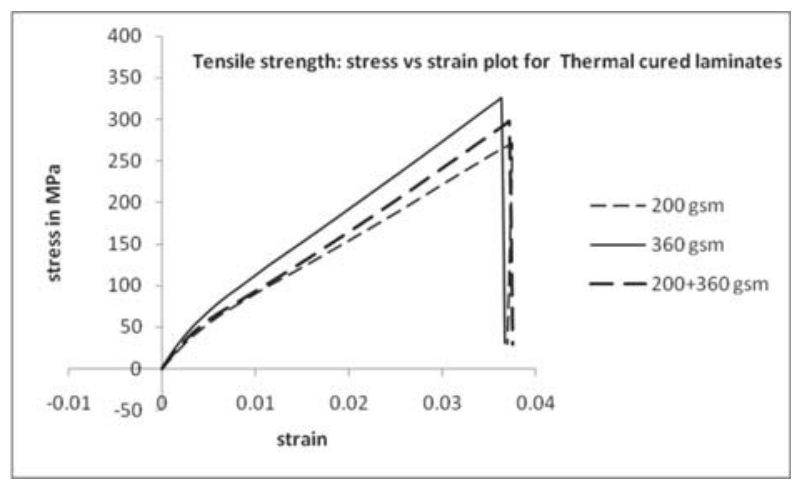

Fig. 2. Tensile strength stress vs strain plot for thermal cured laminates for various combination of reinforcement

The Ultimate tensile strength is calculated by

$$
\text { Tensile Strength }=\frac{P}{b d} M P a
$$

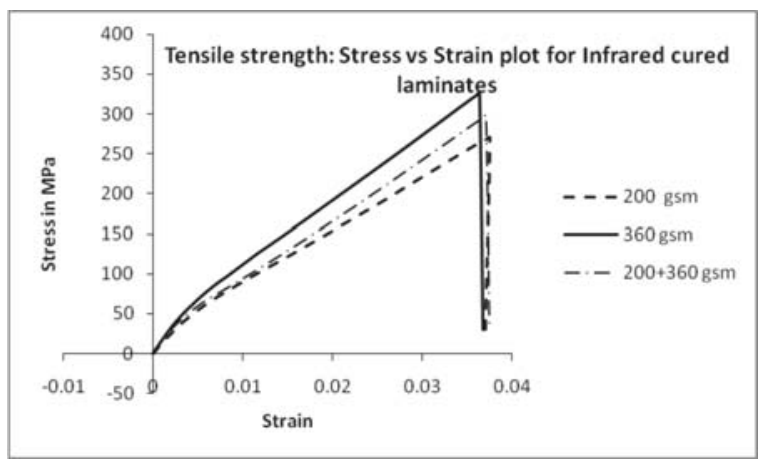

Fig. 3. Tensile Strength- stress vs strain plot for Infrared cured laminates for various combination of reinforcement

The Fig.2 and Fig.3 indicate the stress versus strain behavior of tensile load for both thermal and infrared cured laminates for various types of reinforcement. The plots clearly indicate efficacy of infrared curing and the strength of various laminates. The Fig.4. and Fig.5. shows the variation of Flexural stress versus strain for laminates under various types of glass fiber reinforcement. The Infrared process laminates have similar load carrying capacity or slightly higher in comparison with thermal cured laminates.

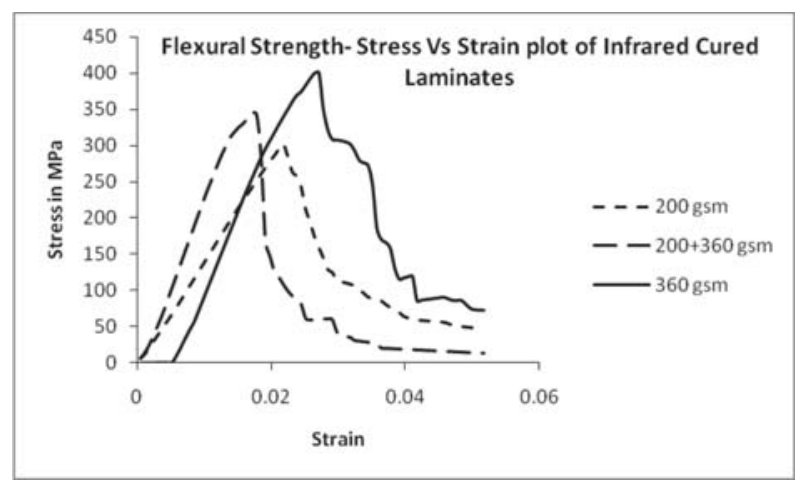

Fig. 4. Flexural stress vs strain plot for infrared cured laminates for various combination of reinforcement.

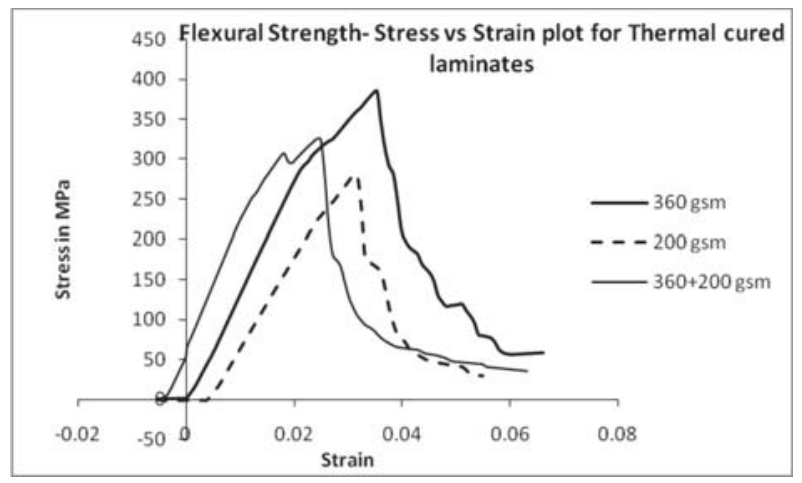

Fig. 5. Flexural stress vs. strain plot for infrared cured laminates for various combination of reinforcement 


\section{B. Hardness test}

Hardness of the samples was obtained using a Shore -D Durometer according to ASTM 2240. Sample was laid on a flat surface and a sharp pointed cone of shore $D$ indentation was obtained on the surface of the laminate sample. Average value was obtained from at least five different positions on the laminate. It is a measure of cure on the surface or the outer layers of the laminate. Since the laminate thickness is less the degree of cure can be analyzed for the entire thickness of laminate

\section{Determination of glass transition temperature $(\mathrm{Tg})$}

The glass transition temperature $(\mathrm{Tg})$ of the thermally (hot-air) cured, IR cured composite samples was determined using a differential scanning calorimeter, DSC $2910 \mathrm{M} / \mathrm{s}$. Waters Inc.,) in general accordance with the procedure outlined in ASTM D 3418 standards. A common heating rate of $10^{\circ} \mathrm{C} / \mathrm{min}$ was employed for evaluating the $\mathrm{Tg}$ values. The maximum $\mathrm{Tg}$ (known) of indicating complete cross linking for standard thermally cured specimens was taken as the basis for confirming completion of cure in IR cured samples. Figure 6.0 and 7.0 shows the $\mathrm{Tg}$

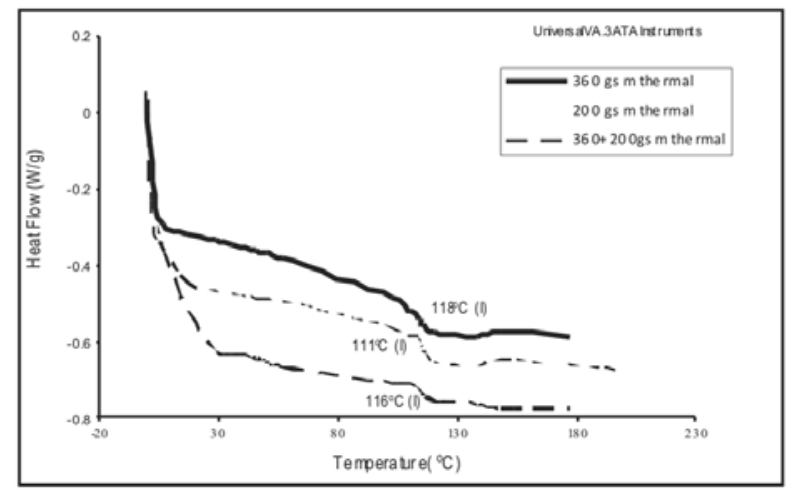

Fig. 6. $\mathrm{Tg}$ thermograms of thermally cured

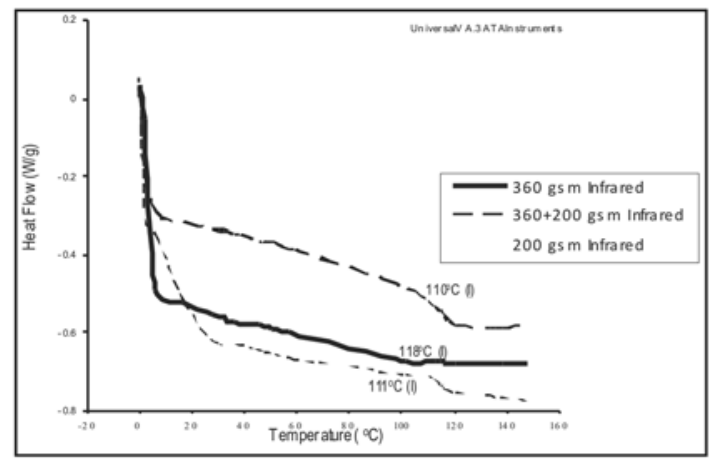

Fig. 7. Infrared cured glass epoxy laminates

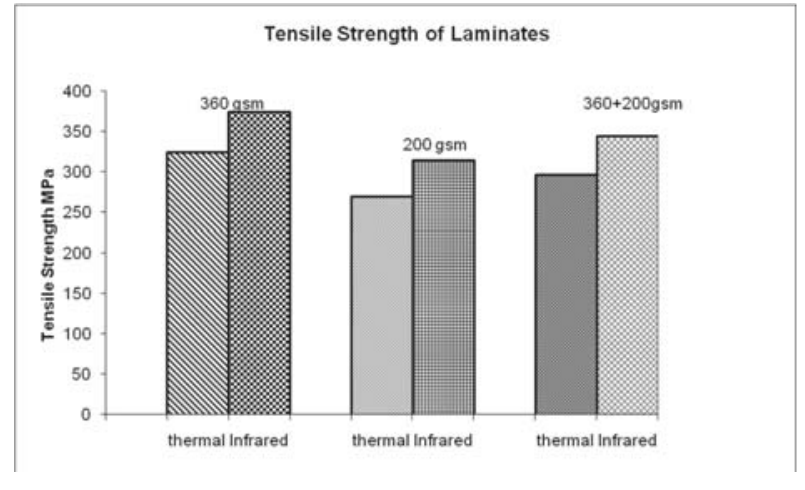

Fig. 8. Comparison of Tensile Strength

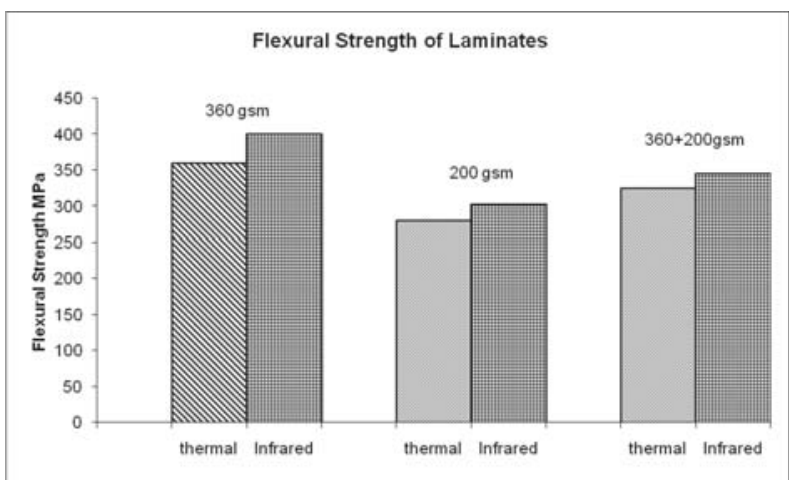

Fig. 9. Flexural strength of Epoxy glass Laminates processed under thermal and infrared curing.

thermograms of both thermal and infrared cured laminates. The degree of cure can be understood by the $\mathrm{Tg}$ value. The range of $\mathrm{Tg}$ values indicates the curing is similar or better in case of Infrared compared to thermal curing.

The tensile and flexural load comparison is shown in figure 8. and 9. A comparison of the thermal data and the mechanical properties of thermally cured and infrared cured glass epoxy composite laminates.

The results of composite laminates processed by Infrared and thermal curing are presented in the Table1. in order to have the comprehensive understanding of the experiments conducted. 
Table 1. Comparison of Experimental results Thermally cured and Infrared cured laminates

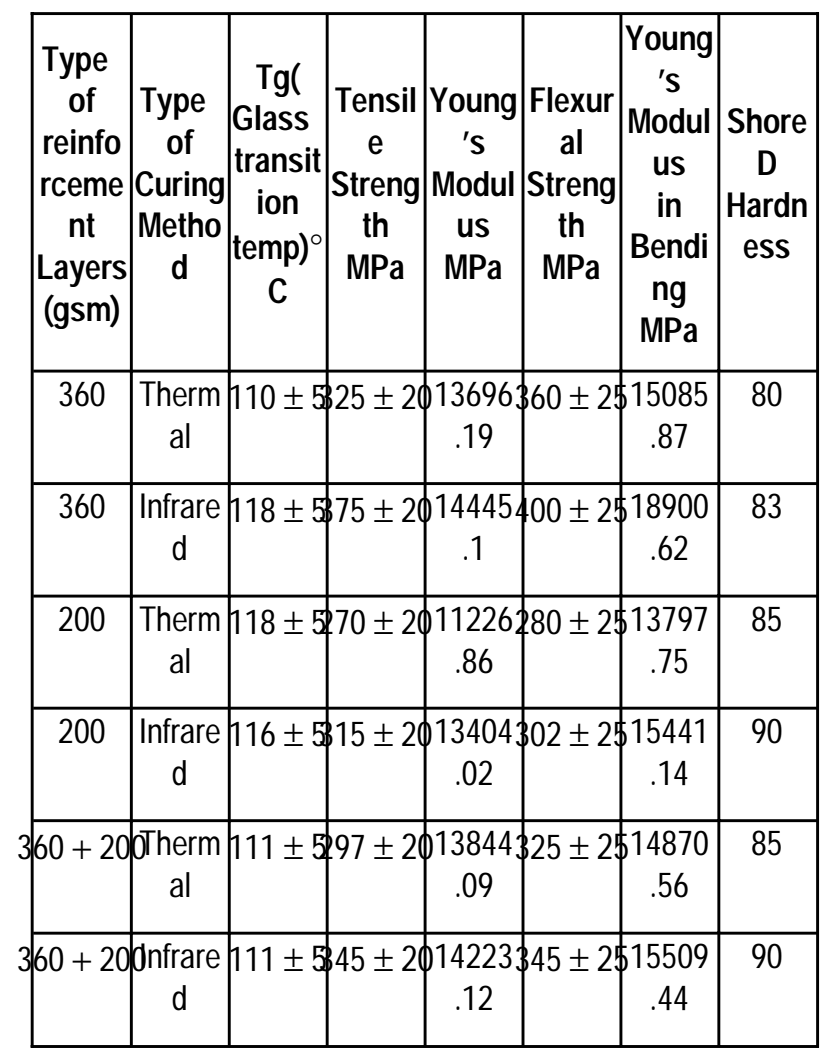

\section{DISCUSSIONS}

Based on the test results it is observed that there is an improvement of 15 percent in tensile strength for Infrared cured laminates in comparison with thermal cured laminates, attributing the fact that better cross linking of monomers has taken place due to volumetric heating mode in Infrared heating process. The FRP Composite cannot be cured in one chosen temperature, it has to be cured under different temperatures by uniformly ramping and soaking for uniform cross linking, better conversion degree and higher mechanical properties. Improved strength can be achieved by curing at elevated temperature. Laminates cured at elevated temperature by infrared method has shown higher value of tensile strength because of better wetting properties of glass fibers with the resin, which leads to higher interfacial strength between the fibers and the resin, thereby offering resistance to tensile load. The $\mathrm{Tg}$ values of Infrared and thermal are comparable indicating better cross linking of monomer molecules that is complete polymerization has taken place, indicating uniform heating of the laminate. Flexural strength has improved marginally up to $5 \%$ in comparison to thermal cure. Infrared curing method is comparable to thermal curing method due to the fact that the infrared radiation is readily absorbed by the polymeric resin and the laminate receives the heat with negligible losses to medium present in between the source and the laminate that is the air. The moisture present in the air may absorb some amount of radiation otherwise the radiation is directly incident on the surface of the laminate. The outer layer of the laminate receives the heat by radiation and inner layers receive the heat by conduction Thereby constituting for lower convective losses. Infrared curing method scores well in comparison to thermal curing. It is an energy efficient method. Infrared applied for processing of polymer composites will reduce the cost and reduces the lead time. Finally the infrared curing is best suited for polymer composite laminates and sandwiching of lower gsm glass fiber layers with higher gsm in the reinforcement leads to improved properties without altering the final thickness of the laminate. 


\section{CONCLUSIONS}

An elevated temperature epoxy amine system as matrix and glass fibers of varying mass density were individually prepared and processed under thermal and infrared curing conditions. The $\mathrm{Tg}$, tensile flexural strength and shore $D$ hardness were determined and compared. The combination $200+360 \mathrm{gsm}$ was also made in order to understand the efficacy of sandwiching the $200 \mathrm{gsm}$ layers with $360 \mathrm{gsm}$ laminates without changing the matrix. The outcome of these studies is presented below:

- The optimized Infrared cure schedule is developed for the epoxy amine system after several trails in the laboratory. The size $200 \times 200 \times 3 \mathrm{~mm}$ thick was kept constant for all the laminates. The distance maintained from infrared heating source to laminate was around $300 \mathrm{~mm}$ which was kept constant and the common stainless steel chamber of volume $400 \mathrm{x} 400 \times 400 \mathrm{~mm}$ with $50 \mathrm{~mm}$ thick ceramic insulation was utilized for conducting the experiments.

- The $\mathrm{Tg}$ of infrared cured laminates was comparable with those of thermally cured counterparts. Infrared curing is a viable source for curing as an alternative to thermal curing

- The tensile strength and young's modulus of laminates of Infrared cured laminates are higher compared to thermal cured as shown in figure 8.0 the result of sandwiching the reinforcement obeys the mathematical rule and lies in between those of 360 and 200 gsm laminates.

- In case of 3 point bending the flexural strength is marginally increased in case of Infrared cured laminates in comparison to thermal cured laminates and a similar phenomenon as that of thermal cure is observed in case of laminates having both the combination of 360 and 200 gsm glass fibers.

- Shore D hardness has similar values for all the laminates indicating the same degree of cure and strength.

- The processing time is saved by $40 \%$ in case of infrared curing without compromising the required properties and strength of the laminates.

\section{ACKNOWLEDGEMENT}

The authors wish to acknowledge the support provided by the Principal and Management of BNM Institute of Technology, Bangalore and National Institute of Engineering, Mysore and Head of the Departments of Mechanical Engineering of these Institutes for extending their support in this project work. The Authors particularly thank the support and guidance provided by $\mathrm{Mr}$ M.S.Krupashankara, Consultant, Radiation Curing of Materials. Thanks to Polymer Science Department of Sri Jayachamarajendra College of Engineering, Mysore for extending their cooperation in providing the test facilities.

\section{REFERENCES}

[1] Hancox N.L., 1984, The environmental response of hybrid composites, Journal of mat sci, (19), pp 1969-1979.

[2] Song, H. and Zhang, Z., 1988, Properties of Unidirectional Hybrid Composites, Hybrid Fiber Composites, Beijing University of Aeronautics and Astronautics Press, Beijing, pp. 343-405.

[3] Shenghu Cao, Zhis WU and Xin Wang., 2009, Tensile Properties of CFRP and Hybrid FRP Composites at Elevated Temperatures, Journal of Composite Materials (43),pp. 315-330

[4] Springer, G.S.., 1982, A Model of the Curing Process of Epoxy Matrix Composites. Progress in Science and Engineering of Composites, (T. Hayashi and K.Kawaka, eds.) Japan Society of Composite Materials, PP. 22-35.

[5] Alfered C.Loos and George S. Springer., 1983, Curing of Epoxy Matrix composites. Journal of Composite Materials, (17) pp. 135-169.

[6] Dickson, L.W. and Singh, A., 1988, Radiation Curing Of Epoxies, Radiation Phys Chem., 1(4-6): 587-593.

[7] Fouassier, J.P. and Rabek, J.F. (Eds)., 1993. Radiation Curing In Polymer Science And Technology, Vols. I, II and IV, Elsevier Applied Science, London, New York.

[8] Papas, S.P. (Ed.), 1992, Radiation Curing Science and Technology, Plenum Press, New-York.

[9] Koleske, J.V., 1997, A Radiation Cure Primer, Journal of Coatings Technology, 9(866): 29-38.

[10] Rai N, Pitchumani R., 1997, Optimum, cure cycle for the fabrication of thermosetting matrix Composites, Polymer Composites, (18), 566-81. 
[11] Decker, C., 1996, Photoinitiated Crosslinking Polymerization, Elseiver Sciences Ltd., pp. 596-618, London.

[12] Lohse, F. and Zweifel, H. 1986, Photocrosslinking of Epoxies, Advances in Polymer Science, Epoxy Resins and Composites III, ( 78), pp. 61-82.

[13] Sinclair, J. W., 1992. Effects of Cure Temperature on Epoxy Resin Properties, Journal of Adhesion, (38) pp.219- 234.

[14] Park, I., Lee, D. and Nam, J., 2002, Equivalent Processing Time Analysis of Glass Transition Development in Epoxy/Carbon Fiber Composite Systems, Journal of Applied Polymer Science, (84), pp. 144-145.

[15] Gorovaya, T. A. and Korotkov, V. N. 1996, Quick Cure of Thermosetting Composites, Composites - Part A: Applied Science and Manufacturing, 27(10), pp.953-960.

[16] Yang Z.L. and Lee S., 2002, Heating Cycle Design for Thick Composite Laminates Using Curing Processes for Thin Laminates, Journal of Reinforced Plastics and Composites, 21,pp.1543 - 1560.

[17] Fine A.S. and Springer G.S.,1997, Design of Composite Laminates for Strength, Weight, and Manufacturability, Journal of Composite Materials, (31)(23), pp. 2330 - 2390.

[18] Vauhini R.M., Srinivasan V., Panchagavi V.S., Karthik N., Suresh R., Srikanth L., and Vanaja A., 2206, Heat Transfer Studies on Glass Epoxy Composite Laminates - Effects of Heating Rate and Fiber Fraction, Journal of Reinforced Plastics and Composites, (25),pp. 1353 $-1365$.

[19] Singer, Stephen M. and JowJinder., 1989,. Effects of Processing on Tensile Properties of an Epoxy/Amine Matrix: Continuous Electromagnetic and/or Thermal Curing, SAMPE Quart, 20(2): pp.14-18.

[20]. BlH-Chern Chern, Tess J Moon and John N R Howell.,2002, On line processing of Unidirectional Fiber composites using Radiative Heating : Experimental validation and process parameter selection. Journal of Composite Materials (36), pp. 1905-1934.

[21] Ali Belhamra, Rabah Diabi and Abdallah Moussaoui.,2007,Technology and Applications of Infrared Heating in Industrial Area, Journal of Engineering and Applied Sciences 2(7), pp.1183-1187.

[22] Kirankumar.P, Ragahavendra N.V. and Sridhara B.K., 2009, Comparitive Analysis of Infrared cured and thermal cured Glass fiber Reinforced Polymer Composite Laminates, International Conference on Advanced Composites in Construction, University of Edinburgh

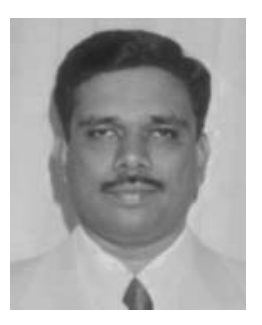

Kiran Kumar. $\mathbf{P}$ is pursuing research in the area of FRP composites since five years. He is working in the Capacity of Assistant professor in the Department of Mechanical Engineering at B.N.M.Institue of Technology, Bangalore. 